\title{
Confidence in eating disorder knowledge does not predict actual knowledge in collegiate female athletes
}

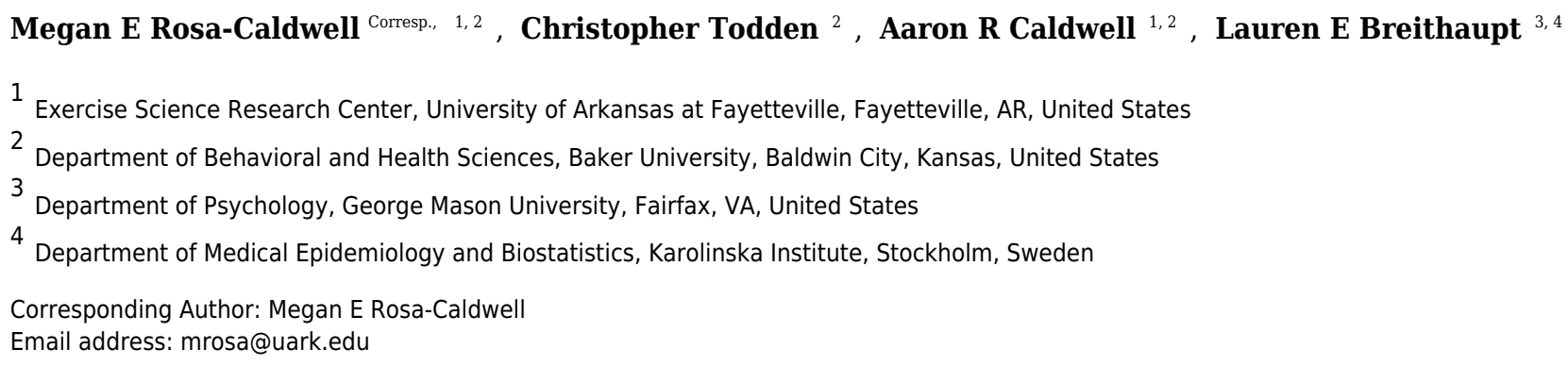

Background: Eating disorders are serious psychological disorders with long term health impacts. Athletic populations, tend to have higher incidences of eating disorders compared to the general population. Yet, there is little known about athletes' eating disorder knowledge and how it relates to their confidence in their knowledge. Therefore, the purpose of our study was to evaluate collegiate female athletes' eating disorder (ED) knowledge and confidence in their knowledge. 51 participants were recruited from a National Association of Intercollegiate Athletics (NAIA) university in the mid-west and asked to complete a 30-question exam assessing one's knowledge of five different categories related to eating disorders. Confidence in the correctness of answers was assessed with a 5 -point Likert-scale ( $1=$ very unconfident, $5=$ very confident). A one-way ANOVA was used to determine differences between scores on different categories and overall scores. A simple regression analysis was used to determine if confidence or age was predictive in knowledge scores. Results: The average score of participants was $69.1 \%, \mathrm{SD}=10.8 \%$ with an average confidence of $3.69 / 5, \mathrm{SD}=0.33$. Athletes scored lowest with regards to Identifying Signs and Symptoms of EDs compared to other sub-scores $(p<0.05)$. There was no relationship between knowledge and confidence scores.

Discussion: There is limited ED knowledge among collegiate female athletes. This may be problematic as many athletes appear confident in the correctness of their answers despite these low scores. Coaches should be aware of this lack of knowledge and work with clinical practitioners, such as dieticians, team physicians and athletic trainers to educate and monitor their athletes on eating disorders, specifically signs and symptoms. 
1 Confidence in Eating Disorder Knowledge does not Predict Actual Knowledge in Collegiate

2 Female Athletes

3 Megan E. Rosa-Caldwell ${ }^{1,2}$, Christopher Todden ${ }^{1}$, Aaron R. Caldwell ${ }^{1,2}$, Lauren E. Breithaupt ${ }^{3,4}$

4

$5{ }^{1}$ Department of Behavioral and Health Sciences, Baker University, Baldwin City, KS, USA

$6{ }^{2}$ Exercise Science Research Center, University of Arkansas, Fayetteville, AR, USA

$7 \quad{ }^{3}$ Department of Psychology, George Mason University, Fairfax, VA, USA

$8{ }^{4}$ Department of Medical Epidemiology and Biostatistics, Karolinska Institute, Stockholm,

9 Sweden

10

11 Corresponding Author: Megan E. Rosa-Caldwell

Email: mrosa@uark.edu

13

14

15

16

17

18

19

20

21

22

23 
Background: Eating disorders are serious psychological disorders with long term health impacts.

Athletic populations, tend to have higher incidences of eating disorders compared to the general population. Yet, there is little known about athletes' eating disorder knowledge and how it relates to their confidence in their knowledge. Therefore, the purpose of our study was to evaluate collegiate female athletes' eating disorder (ED) knowledge and confidence in their knowledge. 51 participants were recruited from a National Association of Intercollegiate Athletics (NAIA) university in the mid-west and asked to complete a 30-question exam assessing one's knowledge of five different categories related to eating disorders. Confidence in the correctness of answers was assessed with a 5-point Likert-scale (1=very unconfident, $5=$ very confident). A one-way ANOVA was used to determine differences between scores on different categories and overall scores. A simple regression analysis was used to determine if confidence or age was predictive in knowledge scores. Results: The average score of participants was $69.1 \%, \mathrm{SD}=10.8 \%$ with an average confidence of $3.69 / 5, \mathrm{SD}=0.33$. Athletes scored lowest with regards to Identifying Signs and Symptoms of EDs compared to other sub-scores $(\mathrm{p}<0.05)$. There was no relationship between knowledge and confidence scores. Discussion: There is limited ED knowledge among collegiate female athletes. This may be problematic as many athletes appear confident in the correctness of their answers despite these low scores. Coaches should be aware of this lack of knowledge and work with clinical practitioners, such as dieticians, team physicians and athletic trainers to educate and monitor their athletes on eating disorders, specifically signs and symptoms. 
47

48

49

50

51

52

53

54

55

56

57

58

\section{Introduction}

Eating Disorders (EDs) are serious mental illnesses affecting millions of individuals worldwide regardless of race, age, nationality, or sex, and are associated with high levels of morbidity and mortality (Chesney, Goodwin, \& Fazel, 2014; Keshaviah et al., 2014; Micali et al., 2015; Schaumberg et al., 2017). The cumulative lifetime risk of an ED is around 4.6\% and an even larger number of individuals (nearly 10\%) meet criteria for a subthreshold ED diagnosis (Hudson, Hiripi, Pope, \& Kessler, 2007). EDs (including anorexia and bulimia) and subthreshold EDs (not fully meeting diagnostic criteria for either anorexia and bulimia) are more prevalent among female athletes compared to non-athletes, and these disordered behavior can dramatically affect an athlete's health and performance (Bratland-Sanda \& Sundgot-Borgen, 2013; Joy, Kussman, \& Nattiv, 2016; Segura-García et al., 2010; Sundgot-Borgen \& Torstveit, 2010). For female athletes, this is a particular concern because energy restriction increases the risk for the female athlete triad, referring to three interrelated health threats, consisting of inadequate energy availability, menstrual disorders, and decreased bone mineral density(De Souza et al., 2014; Nattiv et al., 2007). Considering these pathologies can largely impact future bone and musculoskeletal health as well as quality of life, (Mueller et al., 2015; Palacios, Neyro, Fernandez de Cabo, Chaves, \& Rejas, 2014) it is imperative to identify and treat disordered eating behaviors and EDs as early as possible (Montenegro, 2006; Papathomas \& Lavallee, 2012; Sundgot-Borgen \& Torstveit, 2010).

A substantial amount of research exists on ED risk and prevalence within athletes at large universities (e.g., NCAA Division I and II) (Abood, Black, \& Birnbaum, 2004; DiPasquale \& Petrie, 2013; Gutgesell, Moreau, \& Thompson, 2003; Nagel, Black, Leverenz, \& Coster, 2000; Rosen, McKeag, Hough, \& Curley, 1986; Sanford-Martens, Davidson, Yakushko, Martens, \& 
Hinton, 2005; Roberta Trattner Sherman, Thompson, Dehass, \& Wilfert, 2005; R. T. Sherman, Thompson, DeHass, \& Wilfert, 2005; Sundgot-Borgen \& Torstveit, 2010; Turner \& Bass, 2001). However, little research has been completed at institutions with smaller athletic programs, for example National Association of Intercollegiate Athletics (NAIA) universities. NAIA universities $(<2,000$ students $)$ often lack the resources that are readily available at larger universities, such as access to team-specific physicians, team-specific athletic trainers, or dieticians. Furthermore, recent literature suggests that small universities may have higher prevalence of mental illnesses, including disordered eating (Eisenberg, Hunt, \& Speer, 2013). Therefore, athletes at small universities represent an underrepresented research population with unique requirements for identification and treatment of disordered eating in athletes compared to larger universities.

In general, teammates and coaches spend a significant amount of time together, often times consuming multiple meals a week together. As such teammates and coaches may have the greatest opportunity to identify inappropriate eating behaviors and advocate professional treatment by allied health provider(R. T. Sherman et al., 2005). However, athletes and coaches generally do not have sufficient knowledge of ED behaviors or appropriate nutrition knowledge (Govero \& Bushman, 2003; Torres-McGehee et al., 2011; Turk \& Prentice, 1999) . A significant gap in ED knowledge is evident in prior research in coaches (Torres-McGehee et al., 2012; Turk \& Prentice, 1999). This trend of inadequate knowledge is comparable with that of studentathletes (Torres-McGehee et al., 2011). These studies suggest that lack of knowledge may be a potential problem for collegiate athletics and amplify the difficulty with identifying problematic eating behaviors before they develop into pathological EDs. 
93 Kruger effect). The Dunning Kruger effect, first described in the 1990s (Kruger \& Dunning,

94 1999) describes the phenomena where an individual may perceive high confidence in their

95 knowledge on a subject when in fact, the individual does not have the ability to recognize the

96 limitation of their knowledge. Coaches or teammates who are unable to recognize problematic

97 eating behavior but having confidence in their ability to do can have serious ramifications.

98 However, to our knowledge, no study has specifically investigated how athletes' confidence in

99 their knowledge relates to their actual knowledge in NAIA athletes. Therefore, the purpose of

100 this study was to NAIA female athletes' ED knowledge, confidence in their knowledge, and if

101 confidence positively or negatively predicts ED knowledge. We hypothesized that female

102 athletes would not have sufficient ED knowledge, but despite insufficient knowledge, would

103 have high confidence in their ability to address EDs.

104

105

106

107

108

109

110

111

112

113

114 


\section{Participants}

All procedures were approved by the Baker University Institutional Review Board.

118 Participants were recruited be email from a small National Association of Intercollegiate Athletics

119 (NAIA) institution in the Midwest. Participants were recruited by email inviting them to participate

120 in the study. Inclusion criteria included: female college students actively participating in

121 University-sponsored athletics. After giving informed consent, athletes were sent a link to the

122 online exam. Exclusion criteria included: non-participation in University-sponsored athletics, not

123 having access to a computer with internet access, or being male. 51 female athletes responded and 124 completed the study.

\section{Protocols}

If an athlete chose to participate she was forwarded the informed consent documentation,

which outlined justification for participant recruitment, outlined any risks and benefits, and

confirmed confidentiality for all participants. Participants then completed a demographic questionnaire and an exam on eating disorder content knowledge (described below). Athletes were free to take the exam at their convenience; the survey of demographic data and exam took approximately 20 minutes.

\section{Instruments}

Participants first responded to demographics questions regarding their sport participation and age. Participants then completed a 30 question True/False exam that included questions

137 regarding signs/symptoms, risk factors, etiology, prevention, education, management and 
138 treatment of EDs as previously described (Turk et al., 1999). The exam has been previously utilized 139 to study the concept of eating disorder knowledge (Govero \& Bushman, 2003; Torres-McGehee 140 et al., 2011; Turk \& Prentice, 1999).Each subscale is scored individually and total scores are 141 calculated from the sum of correct responses. Additionally, participants were asked to assess their 142 confidence in the correctness of each response ( $1=$ not very confident, $5=$ very confident) (Turk \& 143 Prentice, 1999). Originally formatted by Turk in 1999, the survey has been verified by specialists 144 in the field of athletic training and ED specialist providers (Turk \& Prentice, 1999). The original 145 survey utilized at 1-4 scale for confidence(Turk \& Prentice, 1999), however to have more 146 quantitative data for regression analysis, we changed the scale to 1-5 scale. While the survey has 147 never specifically been validated in previous research, the 30-question true-false exam 148 demonstrated reasonable difficulty $(\mathrm{p}=0.61, \quad \mathrm{SD}=0.25)$ despite a somewhat low 149 Cronbach Coefficient $\alpha$ value $(\alpha=0.57)$, suggesting the instrument was a reasonable measure of 150 ED knowledge. Additionally, confidence scores demonstrated good internal reliability with a 151 Cronbach Coefficient $\alpha=0.80$.

\section{Statistical Analysis}

A power analysis was conducted using $\mathrm{G}^{*}$ Power to determine an appropriate samples size (Faul, 2009). While we did not hypothesize a specific $\mathrm{R}^{2}$ for the relationship between confidence and overall score, we a priori determined that a $\mathrm{R}^{2}<0.15$ was negligible in this population, and therefore used this value to base power calculations. With an effect size of 0.38 , a $\beta=0.80$, and $\alpha=0.05$, we determined a sample size of approximately 52 was reasonable for this study. Descriptive statistics were used to describe raw and themed scores among the entire population. Adequate knowledge was determined to be at least $80 \%$ correct, has previously 
161 described using the same survey (Govero \& Bushman, 2003; Torres-McGehee et al., 2011).

162 Results for each subscale (signs/symptoms, risk factors, etiology, prevention, education, 163 management) were determined by adding the number of correct responses for each question in the 164 subscale, then dividing the total number of questions in that subscale to determine an average 165 percent correct for each subscale. This same process was also used to determine average 166 confidence for all domains.

167 To determine differences among subscale means and average confidence within subscales, 168 a one-way ANOVA was used with a Tukey-Kramer post-hoc. Additionally, to determine if 169 confidence was predictive of a higher score, simple regression analysis was performed on each of 170 these predictor variables. Upon visual inspection of the data, we noticed older athletes $(>20$ years 171 old) appeared to score higher than younger athletes $(<20$ years old $)$ therefore, as an exploratory 172 analysis we also conducted regression analysis on age in relation to overall scores. 173 Cronbach Coefficient $\alpha$ was determined to estimate internal consistency reliability. Significance 174 was denoted at $\mathrm{p}<0.05$. All data were analyzed with Statistical Analysis System (SAS, version 9.3, 175 Cary, NC) and are presented at MEAN \pm STD. Statistical differences are denoted by different 176 letters in figures, where groups that share letters have means that are not statistically different. 
A total of 51 college athletes (mean age $=19.7, \mathrm{SD}=1.3$ ) enrolled in the study and completed

186

187

188

189

190

191

192

193

194

195

196

197

198

199

200

201

202

203

204

205

206 all measures. Demographics of sport participation can be found in Table 1. Of the 51 college athletes, the average score of eating disorder knowledge was $69.1 \%, \mathrm{SD}=10.8 \%$ and in general, individuals were fairly confidence in their knowledge (mean=3.67/5, SD=0.33). Twelve participants $(23.4 \%)$ scored an adequate score $(>80 \%)$, with the remaining participants 39 participants receiving unsatisfactory scores $(<80 \%)$.

Of the five subscales (signs/symptoms, risk factors, etiology, prevention, education, management), identifying risk factors had the highest average percentage (mean=81\%, $\mathrm{SD}=14.4 \%)$ compared to all other subscales $(\mathrm{p}<0.05)$ (Figure 1$)$. Whereas, identifying signs and symptoms subscale was lower than every domain other than the etiology subscale (mean $=57.2 \%$, $\mathrm{SD}=21.1 \%, \mathrm{p}<0.05$ ). There were no other differences noted between groups (Figure 1). Interestingly, confidence scores were not different on any subscales (Figure 2).

Regression analysis demonstrated no relationship between confidence and total knowledge scores $\left(F(1,49)=1.94, R^{2}=0.038, b=0.063, p>0.05\right)$ (Supplementary Figure 1). Through an exploratory analysis we also found a small but statistically significant relationship between participant age and total knowledge scores $\left(F(1,49)=9.17, \mathrm{R}^{2}=0.16, \mathrm{~b}=.0321, \mathrm{p}<0.05\right)$ was noted (Supplementary Figure 2). 


\section{Discussion}

To our knowledge, we are the first group to analyze eating disorder knowledge

specifically in NAIA athletes. The student athletes surveyed lacked eating disorder knowledge,

specifically they scored the lowest on the identification of ED signs and symptoms domain.

More so confidence in perceived knowledge was not predicative of actual knowledge regarding

ED knowledge. These results provide preliminary evidence that student athletes do not recognize

214 behaviors.

After a preliminary analysis of the data, we noticed a relationship between age and

216

217

218

219

220

221

222

223

224

225

226

227

228

229

age and overall ED knowledge. We found a small relationship between athlete age and increased scores; to our knowledge this is the first study to compare knowledge in relation to athletes' age.

It is possible that older students have received knowledge through an outside source during their time at college, such as a nutrition course or a seminar on EDs not specifically sponsored by athletics or some educational program. However, due to limitations of the survey, it is impossible to determine why the older students tended to have higher knowledge compared to younger.

However, because this was an exploratory analysis, not the original aims of the study, we urge a cautious interpretation of the data and encourage future research to investigate mechanisms by which age may influence knowledge of EDs.

Overall, many participants did not have appropriate ED knowledge ( $>80 \%)$, however participants still tended to be confident in the accuracy of their knowledge (average confidence $>3.5 / 5$ ). The results are consistent with previous research utilizing this survey (Torres-McGehee et al., 2011; Turk \& Prentice, 1999), and others that have investigated similar domains (Torres- 
230 McGehee et al., 2012) demonstrating little knowledge, but high confidence in perceived

231 knowledge. This discrepancy in knowledge and confidence has been seen across many

232 psychological domains (Pennycook, Ross, Koehler, \& Fugelsang, 2017; Simons, 2013).

233 Specifically, for this population, their lack of knowledge in relation to their confidence

234 represents a potential health risk for female student athletes. Depending on the university's

235 resources, there may be limited information available to athletes regarding healthy weight loss

236 and nutrition (R. T. Sherman et al., 2005). Thus, athletes often ask teammates for nutritional

237 advice (Bond et al., 2008; Reel \& Gill, 1996; Turocy et al., 2011). However, the accuracy of this

238 advice may be questionable (Torres-McGehee et al., 2012; Turk \& Prentice, 1999; Turner \&

239 Bass, 2001; Wiita \& Stombaugh, 1995), yet our data suggests that they may still be confident in

240 their knowledge, which could contribute to unhealthy eating behaviors.

241 The ability to identify signs and symptoms was the lowest subdomain in this population.

242 This is concerning as teammates are often in a position to recognize problematic eating behaviors

243 and suggest further treatment due to amount of time spent together (R. T. Sherman et al., 2005).

244 This may be especially true of athletes at NAIA universities, which may share practitioners with

245 training in nutrition, such athletic trainers, across multiple teams. Athletic trainers monitoring

246 multiple teams may limit opportunities to identify unhealthy eating behaviors. If teammates do

247 not know what behaviors are associated with EDs, then other teammates engaging in

248 pathological eating behaviors may go unnoticed. Moreover, unhealthy eating behaviors may

249 even by encouraged by uniformed teammates. Our data demonstrate the many collegiate female

250 athletes are not familiar with symptoms of EDs and suggests they may not recognize these

251 unhealthy behaviors in teammates. Taken together, a lack in knowledge by fellow teammates as

252 well as limited athletic training staff may lead to unnoticed unhealthy eating behaviors, placing 
253 female athletes in NAIA athletic programs at probable risk. However, we should note that this

254 study was only conducted at one institution, therefore the results are fairly preliminary and this

255 research topic should be further investigated across multiple NAIA universities.

256 In conclusion, this study reiterates there is poor knowledge of EDs among female

257 collegiate athletes. This is the first study to investigate participants at small collegiate athletic

258 programs, an underrepresented population in the field. Specifically, our data demonstrate that

259 female student athletes clearly lack the knowledge to identify the signs and symptoms of

260 disordered eating in their peers, yet have high confidence in their capacity to do so. Coaches,

261 athletic directors and athletic trainers should be educated on these conditions and educate their

262 respective athletes on EDs. While it should not be the expectation that athletes understand the

263 intricacies of nutrition and EDs, due to the large time spent with teammates, they are likely in the

264 optimal position to notice unhealthy eating behaviors in teammates, and it would be beneficial

265 for them to understand early indicators of problematic eating behaviors and advocate treatment;

266 this may help alleviate the occurrence of full blown EDs or catch disorders early.

267

268

269

270

271

272

273

274

275

276 
278

Abood, D. A., Black, D. R., \& Birnbaum, R. D. (2004). Nutrition education intervention for college female athletes. J Nutr Educ Behav, 36(3), 135-137.

Bond, C. M., Bonci, L. J., Granger, L. R., Johnson, C. L., Malina, R. M., Milne, L. W., . . . Vanderbunt, E. M. (2008). National Athletic Trainers' Association Position Statement: Preventing, Detecting, and Managing Disordered Eating in Athletes. Journal of Athletic Training (National Athletic Trainers' Association), 43(1), 80-108.

Bratland-Sanda, S., \& Sundgot-Borgen, J. (2013). Eating disorders in athletes: overview of prevalence, risk factors and recommendations for prevention and treatment. Eur J Sport Sci, 13(5), 499-508. doi:10.1080/17461391.2012.740504

Chesney, E., Goodwin, G. M., \& Fazel, S. (2014). Risks of all-cause and suicide mortality in mental disorders: a meta-review. World Psychiatry, 13(2), 153-160. doi:10.1002/wps.20128

De Souza, M. J., Nattiv, A., Joy, E., Misra, M., Williams, N. I., Mallinson, R. J., . . Matheson, G. (2014). 2014 Female Athlete Triad Coalition Consensus Statement on Treatment and Return to Play of the Female Athlete Triad: 1st International Conference held in San Francisco, California, May 2012 and 2nd International Conference held in Indianapolis, Indiana, May 2013. Br J Sports Med, 48(4), 289. doi:10.1136/bjsports-2013-093218

DiPasquale, L. D., \& Petrie, T. A. (2013). Prevalence of Disordered Eating: A Comparison of Male and Female Collegiate Athletes and Nonathletes. Journal of Clinical Sport Psychology, 7(3), 186-197. 
298 Eisenberg, D., Hunt, J., \& Speer, N. (2013). Mental health in American colleges and universities:

299

300

301

302

303

304

305

306

307

308

309

310

311

312

313

314

315

316

317

318

319 variation across student subgroups and across campuses. $J$ Nerv Ment Dis, 201(1), 60-67. doi:10.1097/NMD.0b013e31827ab077

Faul, F., Erdfelder, E., Buchner, A., \& Lang, A.-G. (2009). Statistical power analyses using G*Power 3.1: Tests for correlation and regression analyses. Behavior Research Methods, 41, 1149-1160.

Govero, C., \& Bushman, B. A. (2003). Collegiate cross country coaches' knowledge of eating disorders. Women in Sport \& Physical Activity Journal, 12(1), 53-65.

Gutgesell, M. E., Moreau, K. L., \& Thompson, D. L. (2003). Weight Concerns, Problem Eating Behaviors, and Problem Drinking Behaviors in Female Collegiate Athletes. J Athl Train, $38(1), 62-66$.

Joy, E., Kussman, A., \& Nattiv, A. (2016). 2016 update on eating disorders in athletes: A comprehensive narrative review with a focus on clinical assessment and management. $\mathrm{Br}$ J Sports Med, 50(3), 154-162. doi:10.1136/bjsports-2015-095735

Keshaviah, A., Edkins, K., Hastings, E. R., Krishna, M., Franko, D. L., Herzog, D. B., .. . Eddy, K. T. (2014). Re-examining premature mortality in anorexia nervosa: a meta-analysis redux. Compr Psychiatry, 55(8), 1773-1784. doi:10.1016/j.comppsych.2014.07.017

Kruger, J., \& Dunning, D. (1999). Unskilled and unaware of it: How difficulties in recognizing one's own incompetence lead to inflated self-assessments. Journal of Personality and Social Psychology, 77(6), 1121-1134.

Micali, N., Solmi, F., Horton, N. J., Crosby, R. D., Eddy, K. T., Calzo, J. P., . . Field, A. E. (2015). Adolescent Eating Disorders Predict Psychiatric, High-Risk Behaviors and 
Weight Outcomes in Young Adulthood. J Am Acad Child Adolesc Psychiatry, 54(8), 652-659 e651. doi:10.1016/j.jaac.2015.05.009

322

323

324

325

326

327

328

329

330

331

Montenegro, S. O. (2006). Disordered Eating in Athletes. Athletic Therapy Today, 11(1), 60-62.

Mueller, S. M., Immoos, M., Anliker, E., Drobnjak, S., Boutellier, U., \& Toigo, M. (2015). Reduced Bone Strength and Muscle Force in Women 27 Years After Anorexia Nervosa. J Clin Endocrinol Metab, 100(8), 2927-2933. doi:10.1210/jc.2015-1011

Nagel, D. L., Black, D. R., Leverenz, L. J., \& Coster, D. C. (2000). Evaluation of a screening test for female college athletes with eating disorders and disordered eating. $J$ Athl Train, 35(4), 431-440.

Nattiv, A., Loucks, A. B., Manore, M. M., Sanborn, C. F., Sundgot-Borgen, J., \& Warren, M. P. (2007). American College of Sports Medicine position stand. The female athlete triad. Med Sci Sports Exerc, 39(10), 1867-1882. doi:10.1249/mss.0b013e318149f111

Palacios, S., Neyro, J. L., Fernandez de Cabo, S., Chaves, J., \& Rejas, J. (2014). Impact of osteoporosis and bone fracture on health-related quality of life in postmenopausal women. Climacteric, 17(1), 60-70. doi:10.3109/13697137.2013.808182

Papathomas, A., \& Lavallee, D. (2012). Eating Disorders in Sport : a call for methodological diversity. Revista de psicología del deporte, 21(2), 387-392.

Pennycook, G., Ross, R. M., Koehler, D. J., \& Fugelsang, J. A. (2017). Dunning-Kruger effects in reasoning: Theoretical implications of the failure to recognize incompetence. Psychon Bull Rev, 24(6), 1774-1784. doi:10.3758/s13423-017-1242-7

Reel, J. J., \& Gill, D. L. (1996). Psychosocial Factors Related to Eating Disorders Among High School and College Female Cheerleaders. Sport Psychologist, 10(2), 195-206. 
342 Rosen, L. W., McKeag, D. B., Hough, D. O., \& Curley, V. (1986). Pathogenic weight-control behavior in female athletes. / Comportement des athletes femmes face aux regimes amaigrissants. Physician \& Sportsmedicine, 14(1), 79-84.

Sanford-Martens, T., Davidson, M., Yakushko, O., Martens, M., \& Hinton, P. (2005). Clinical and Subclinical Eating Disorders: An Examination of Collegiate Athletes. Journal of Applied Sport Psychology, 17(1), 79-86.

Schaumberg, K., Welch, E., Breithaupt, L., H übel, C., Baker, J., Munn-Chernoff, M., . . Bulik, C. (2017). The science behind the academy for EDs' nine truths about EDs. $<p$ class="MsoListParagraph" style="margin:0in;margin-bottom:.0001pt;mso-addspace:auto;line-height:normal;mso-pagination:none;mso-layout-grid-align:none;textautospace:none"> European EDs Review, (in press).

Segura-García, C., Ammendolia, A., Procopio, L., Papaianni, M. C., Sinopoli, F., Bianco, C., .. . Capranica, L. (2010). Body uneasiness, eating disorders, and muscle dysmorphia in individuals who overexercise. $J$ Strength Cond Res, 24(11), 3098-3104. doi:10.1519/JSC.0b013e3181d0a575

Sherman, R. T., Thompson, R. A., Dehass, D., \& Wilfert, M. (2005). NCAA Coaches Survey: The Role of the Coach in Identifying and Managing Athletes with Disordered Eating. Eating Disorders, 13(5), 447-466.

Sherman, R. T., Thompson, R. A., DeHass, D., \& Wilfert, M. (2005). NCAA coaches survey: the role of the coach in identifying and managing athletes with disordered eating. Eat Disord, 13(5), 447-466. doi:10.1080/10640260500296707 
363 Simons, D. J. (2013). Unskilled and optimistic: overconfident predictions despite calibrated

364 knowledge of relative skill. Psychon Bull Rev, 20(3), 601-607. doi:10.3758/s13423-013-

365

366

367

368

369

370

371

372

373

374

375

376

377

378

379

380

381

382

383

384

385

0379-2

Sundgot-Borgen, J., \& Torstveit, M. K. (2010). Aspects of disordered eating continuum in elite high-intensity sports. Scand J Med Sci Sports, 20 Suppl 2, 112-121. doi:10.1111/j.16000838.2010.01190.x

Torres-McGehee, T. M., Leaver-Dunn, D., Green, J. M., Bishop, P. A., Leeper, J. D., \& Richardson, M. T. (2011). Knowledge of eating disorders among collegiate administrators, coaches, and auxiliary dancers. Percept Mot Skills, 112(3), 951-958. doi:10.2466/02.13.PMS.112.3.951-958

Torres-McGehee, T. M., Pritchett, K. L., Zippel, D., Minton, D. M., Cellamare, A., \& Sibilia, M. (2012). Sports nutrition knowledge among collegiate athletes, coaches, athletic trainers, and strength and conditioning specialists. J Athl Train, 47(2), 205-211.

Turk, J. C., \& Prentice, W. E. (1999). Collegiate coaches' knowledge of eating disorders. Journal of Athletic Training (National Athletic Trainers' Association), 34(1), 19.

Turner, L. W., \& Bass, M. A. (2001). Osteoporosis knowledge, attitudes, and behaviors of female collegiate athletes. Int J Sport Nutr Exerc Metab, 11(4), 482-489.

Turocy, P. S., DePalma, B. F., Horswill, C. A., Laquale, K. M., Martin, T. J., Perry, A. C., .. . Association, N. A. T. (2011). National Athletic Trainers' Association position statement: safe weight loss and maintenance practices in sport and exercise. J Athl Train, 46(3), $322-336$.

Wiita, B., \& Stombaugh, I. (1995). Nutrition knowledge and eating practices of young female athletes. JOPERD: The Journal of Physical Education, Recreation \& Dance, 66(3), 36. 


\section{Table $\mathbf{1}$ (on next page)}

Descriptive statistics of sports played by athletes in the current study

Number of individual participants in each sport. 


\begin{tabular}{|ll|}
\hline Sport & n \\
\hline Cheer/Dance & 7 \\
Cross Country/Distance Running & 8 \\
Golf & 1 \\
Basketball & 4 \\
Soccer & 9 \\
Tennis & 2 \\
Track-Sprints/Jumps & 8 \\
Track-Throws & 1 \\
Volleyball & 6 \\
Softball & 5 \\
\hline
\end{tabular}

1 


\section{Figure 1}

Scores on domains of eating disorder knowledge

Subscale scores from the present study. The percent for each subscale was the sum of correct answers divided by the sum of total questions. The percents for all participants were then averaged to determine overall average percent. $\mathbf{a}$ - denotes a significant difference from etiology, signs and symptoms, management, and education. $\mathbf{b}$ - denotes a significant difference from signs and symptoms and risk factors. c- denotes a significant difference from management, risk factors, and education. The subscales sharing letters are not significantly different $(p>0.05)$. 


\section{Subscale Scores}

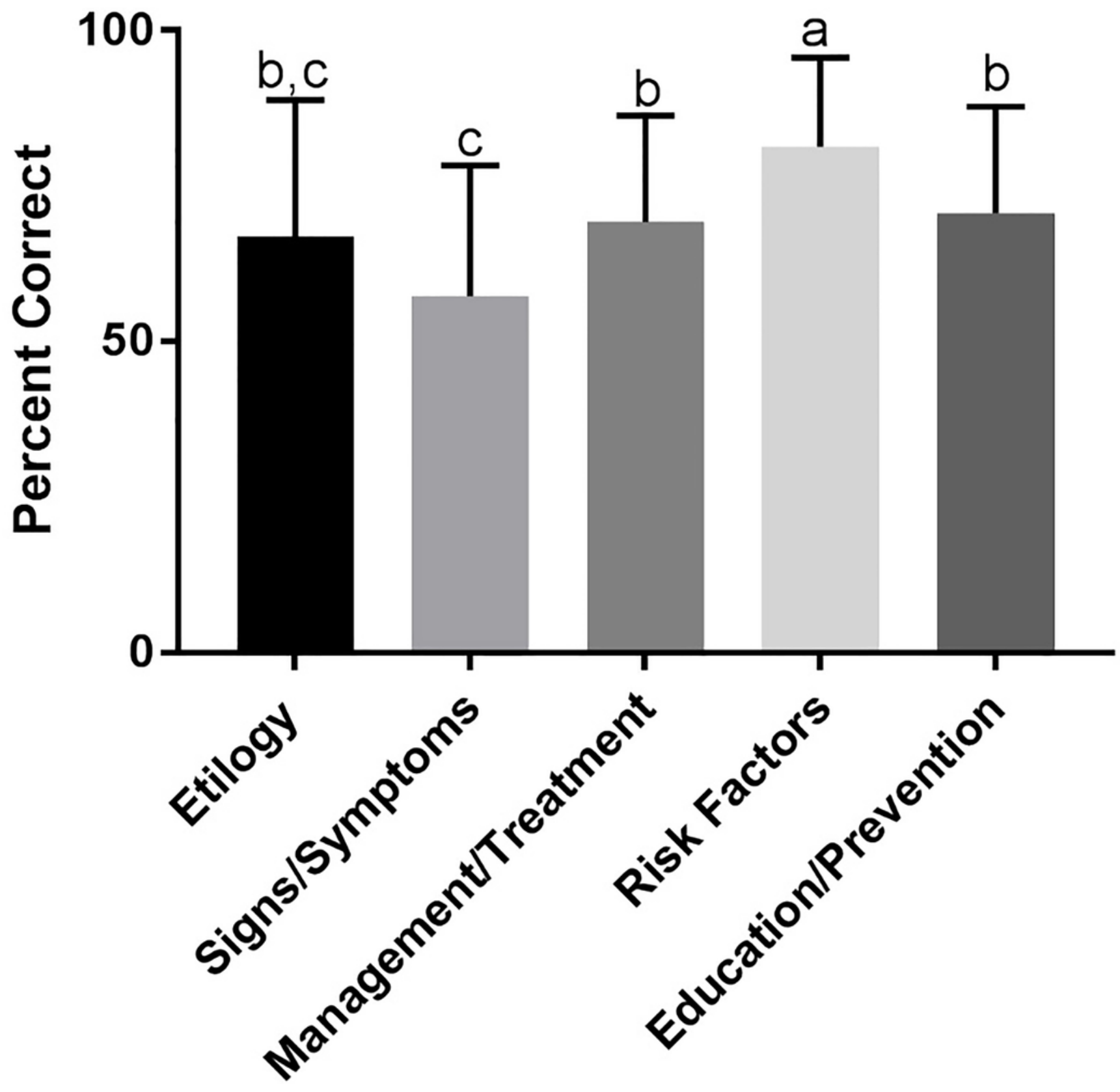




\section{Figure 2}

Average confidence of knowledge on various domains of eating disorder information

Confidence values for subscales from the present study. The confidence for each question was summed and then divided by the total possible confidence (corresponding to a confidence score of 5 for each question), equating to the participant's average confidence for that category. Average confidence was then averaged to determine an overage mean confidence for that category. $\mathbf{a}$ - denotes a significant difference from etiology. $\mathbf{b}$ - denotes a significant difference from education. Therefore, subscales sharing letters are not significantly different $(p>0.05)$. 


\section{Confidence}

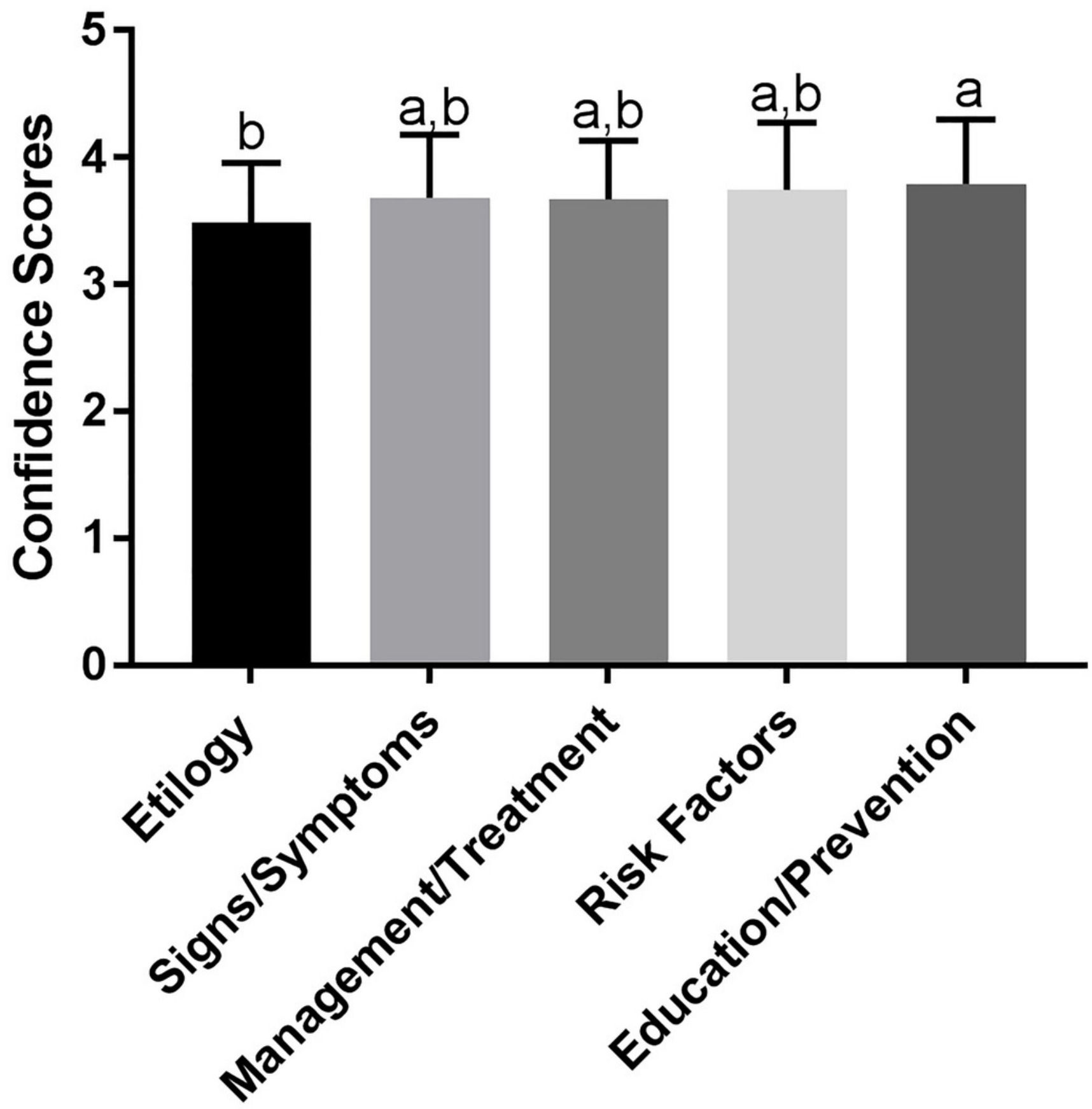

